motor phenotypes of HSPs. It also remains unclear whether pure HSPs can be linked to cell-autonomous processes or are non-cell autonomous, and indeed whether there are "protective" features in nonspinal targets of upper motoneurons that result in some sparing of neuronal function.

In summary, Beetz and colleagues have generated what promises to be a very useful mouse model of HSP. Future studies of these mice should uncover important features of the pathogenic mechanisms underlying this disease. These mice will also be useful in developing a deeper understanding of ER membrane biology. It is likely that we will "REEP" the benefit of this work for some years to come.

\section{Acknowledgments}

Supported in part by NIH grants (MH077298, to A.Y. Deutch; MH063232 and NS078291, to R.J. Colbran; and NS057666, to P. Hedera).

Address correspondence to: Ariel Y. Deutch, Vanderbilt Brain Institute, 8122 MRBIII, $46521^{\text {st }}$ Ave. South, Nashville, Tennessee 37232, USA. Phone: 615.327.7090; E-mail: ariel.deutch@vanderbilt.edu.
1. DeLuca GF, Ebers GC, Esiri MM. The extent of axonal loss in the long tracts in hereditary spastic paraplegia. Neuropath Appl Neurobiol. 2004;30(6):576-584.

2. White $\mathrm{KD}$, et al. Clinical and pathologic findings in hereditary spastic paraparesis with spastin mutation. Neurology. 2000;55(1):89-94.

3. Depienne C, Stevanin G, Brice A, Durr A. Hereditary spastic paraplegias: an update. Curr Opin Neurol. 2007;20(6):674-680.

4. Salinas S, Proukakis C, Crosby A, Warner TT. Hereditary spastic paraplegia: clinical features and pathogenetic mechanisms. Lancet Neurol. 2008;7(12):1127-1138.

5. Sauter S, et al. Mutation analysis of the spastin gene (SPG4) in patients in Germany with autosomal dominant hereditary spastic paraplegia. Hum Mutat. 2002;20(2):127-132.

6. Schlang KJ, Arning L, Epplen JT, Stemmler S. Autosomal dominant hereditary spastic paraplegia: novel mutations in the REEP1 gene (SPG31). BMC Med Genet. 2008;9:71.

7. Zuchner S, et al. Mutations in the novel mitochondrial protein REEP1 cause hereditary spastic paraplegia type 31. Am J Hum Genet. 2006; $79(2): 365-369$

8. Beetz C, et al. REEP1 mutation spectrum and genotype/phenotype correlation in hereditary spastic paraplegia type 31. Brain. 2008;131(pt 4):1078-1086.

9. Hewamadduma C, et al. New pedigrees and novel mutation expand the phenotype of REEP1-associated hereditary spastic paraplegia (HSP). Neurogenetics. 2009;10(2):105-110.

10. Goizet C, et al. REEP1 mutations in SPG31: frequency, mutational spectrum, and potential association with mitochondrial morpho-functional dysfunction. Hum Mutat. 2011;32(10):1118-1127.

11. Beetz C, et al. A spastic paraplegia mouse model reveals REEP1-dependent ER shaping. J Clin Invest. 2013;123(10):4273-4282.

12. Friedman JR, Lackner LL, West M, DiBenedetto JR, Nunnari J, Voeltz GK. ER tubules mark sites of mitochondrial division. Science. 2011;334(6054):358-362.

13. Allen Institute for Brain Science. Allen Mouse Brain Atlas. AIBS Web site. http://mouse.brainmap.org/experiment/show/74821680. Accessed August 26, 2013

14. Zhao J, Matthies DS, Botzolakis EJ, Macdonald RL, Blakely RD, Herrera P. Hereditary spastic paraplegia-associated mutations in the NIPA1 gene and its Caenorhabditis elegans homolog trigger neural degeneration in vitro and in vivo through a gain-of-function mechanism. J Neurosci. 2008; 28(51):13938-13951.

15. Park SH, Zhu PP, Parker RL, Blackstone C. Hereditary spastic paraplegia proteins REEP1, spastin, and atlastin- 1 coordinate microtubule interactions with the tubular ER network. J Clin Invest. 2010;120(4):1097-1110.

16. Montenegro G, et al. Mutations in the ER-shaping protein reticulon 2 cause the axon-degenerative disorder hereditary spastic paraplegia type 12 . J Clin Invest. 2012;122(2):538-544.

17. Füger $P$, et al. Spastic paraplegia mutation N256S in the neuronal microtubule motor KIF5A disrupts axonal transport in a Drosophila HSP model. PloS Genet. 2012;8(11):e1003066.

18. Burke RE. Sir Charles Sherrington's the integrative action of the nervous system: a centenary appreciation. Brain. 2007;130(pt 4):887-894.

19. Shepherd GM. Corticostriatal connectivity and its role in disease. Nat Rev Neurosci. 2013;14(4):278-291.

20. Webb S, et al. Autosomal dominant hereditary spastic paraparesis with cognitive loss linked to chromosome 2p. Brain. 1998;121(pt 4):601-609.

\title{
Zinc, insulin, and the liver: a ménage à trois
}

\author{
Thomas V. O'Halloran, ${ }^{1}$ Melkam Kebede, ${ }^{2}$ Steven J. Philips, ${ }^{3}$ and Alan D. Attie ${ }^{2}$ \\ ${ }^{1}$ Chemistry of Life Processes Institute, Departments of Chemistry and Molecular Biosciences, Northwestern University, \\ Evanston, Illinois, USA. ${ }^{2}$ Department of Biochemistry, University of Wisconsin-Madison, Madison, Wisconsin, USA. \\ ${ }^{3}$ Department of Molecular Biosciences, Northwestern University, Evanston, Illinois, USA.
}

\begin{abstract}
Insulin and $\mathrm{Zn}^{2+}$ enjoy a multivalent relationship. $\mathrm{Zn}^{2+}$ binds insulin in pancreatic $\beta$ cells to form crystalline aggregates in dense core vesicles (DCVs), which are released in response to physiological signals such as increased blood glucose. This transition metal is an essential cofactor in insulin-degrading enzyme and several key $\mathrm{Zn}^{2+}$ finger transcription factors that are required for $\beta$ cell development and insulin gene expression. Studies are increasingly revealing that fluctuations in $\mathrm{Zn}^{2+}$ concentration can mediate signaling events, including dynamic roles that extend beyond that of a static structural or catalytic cofactor. In this issue of the JCI, Tamaki et al. propose an additional function for $\mathrm{Zn}^{2+}$ in relation to insulin: regulation of insulin clearance from the bloodstream.
\end{abstract}

Zinc is an abundant and essential element that plays a number of regulatory roles in

Conflict of interest: Thomas V. O'Halloran holds equity positions in Viamet Pharmaceuticals Holdings Inc. and Tactic Pharma. Alan D. Attie was previously a member of the CVMED advisory board for Pfizer

Citation for this article: $J$ Clin Invest. 2013 ; 123(10):4136-4139. doi:10.1172/JCI72325. biology. Studies in model organisms indicate that zinc receptor proteins control complex networks of genes in $\mathrm{Zn}^{2+}$-responsive manners. Moreover, complex developmental events are controlled by dynamic fluctuations of billions of zinc ions between intracellular compartments and extracellular sites $(1,2)$. Secretory compartments enriched in $\mathrm{Zn}^{2+}$ are found in a number of cell types, including hippocampal and olfactory neurons, oocytes, and pancreatic $\beta$ cells. Specific stimulation of these cells leads to $\mathrm{Zn}^{2+}$ exocytosis; however, neither the physiological nor the biochemical roles of the released $\mathrm{Zn}^{2+}$ are yet clear in these systems. In this issue of the JCI, Tamaki et al. describe striking connections among zinc compartmentalization, exocytosis, and insulin uptake by the liver (3).

\section{A link between zinc transport and diabetes}

The ZnT8 transporter (encoded by solute carrier family 30 member 8 gene; SLC30A8) is located on dense core vesicles (DCVs) in $\beta$ cells and loads $\mathrm{Zn}^{2+}$ into these secretory compartments, where it binds with and stabilizes a hexameric form of insulin (4). $\mathrm{ZnT}$ is an autoantigen in type 1 diabetes 
Table 1

Phenotypes observed in previous S/c30a8-KO studies

\begin{tabular}{|c|c|c|c|c|c|}
\hline & $\begin{array}{c}\text { Nicolson et al. } \\
2009(9)^{A}\end{array}$ & $\begin{array}{l}\text { Pound et al. } \\
2009(11)^{\mathrm{A}}\end{array}$ & $\begin{array}{l}\text { Lemaire et al. } \\
2009(12)^{\mathrm{A}}\end{array}$ & $\begin{array}{l}\text { Wijesekara et al. } \\
2010(13)^{B}\end{array}$ & $\begin{array}{l}\text { Pound et al. } \\
2012(10)\end{array}$ \\
\hline$\beta$ cell mass & Normal & Normal & & & \\
\hline Granules & $\begin{array}{l}\text { Empty/atypical/ } \\
\text { rod-shaped }\end{array}$ & & $\begin{array}{l}\text { Complete loss } \\
\text { of DCVs }\end{array}$ & $\begin{array}{l}\text { Empty/atypical/ } \\
\text { rod-shaped }\end{array}$ & \\
\hline Proinsulin processing & Normal & & Normal & Decreased & \\
\hline Glucose during GTT & $\begin{array}{l}\text { Glucose intolerant in } \\
\text { male, normal in female }\end{array}$ & No change & No change & Glucose intolerant & No change \\
\hline Plasma insulin & $\begin{array}{l}\text { Decreased in male, } \\
\text { normal in female }\end{array}$ & $\begin{array}{l}\text { Decreased fasting } \\
\text { insulin }\end{array}$ & No change & No change & $\begin{array}{l}50 \% \text { decrease in male } \\
\text { mixed-background } \mathrm{KO} \text {, } \\
20 \% \text { decrease in female } \\
\text { C57BL/6-background } \mathrm{KO}\end{array}$ \\
\hline GSIS & Enhanced & $33 \%$ decrease & No change & $\begin{array}{l}\text { Decreased first phase, } \\
\text { normal second phase }\end{array}$ & $\begin{array}{l}35 \% \text { in male mixed- } \\
\text { background KO only }\end{array}$ \\
\hline Insulin sensitivity after HFD & Decreased & Normal & Normal & & \\
\hline
\end{tabular}

AWhole-body KO. ${ }^{\mathrm{B}} \beta$ cell-specific KO.

(5), and a W325R SLC30A8 polymorphism is associated with T2D (6). Slc30a8 deletion in mice decreases $\mathrm{DCV} \mathrm{Zn}^{2+}$ content (4, 7-9). A role for decreased $\mathrm{Zn}^{2+}$ in DCV functional defects is not obvious, because some species (e.g., guinea pig) produce insulin molecules that do not bind to $\mathrm{Zn}^{2+}$ but still maintain normal insulin secretion.

Tamaki et al. address contradictory findings concerning the effect of Slc30a8 deletion on insulin secretion in mice (3). Using $\beta$ cell-specific deletion of Slc30a8, they report an insulin hypersecretion phenotype and suggest that functional $\mathrm{ZnT}$ 8 facilitates autocrine and paracrine roles for the $\mathrm{Zn}^{2+}$ burst produced by $\beta$ cells upon glucose stimulation. In the WT animals, the released $\mathrm{Zn}^{2+}$ bolus inhibited further insulin release, while loss of Slc30a8 resulted in sustained insulin secretion. Intriguingly, despite increased insulin secretion, peripheral insulin levels were lower and the $\mathrm{C}$-peptide/insulin ratio was increased in $\mathrm{KO}$ mice. These data indicate that lower insulin levels might be due to increased insulin clearance from the bloodstream. Studies of proinsulin/insulin ratio and rates of insulin clearance in humans with the SLC30A8 W325R polymorphism were also consistent with this idea.

\section{Zinc inhibition of hepatic insulin uptake}

Quantitatively, the liver and the kidneys are the most important sites of insulin uptake and degradation. The liver is the first organ exposed to newly secreted insulin and can clear much of this insulin in a single pass. The authors investigated hepatic insulin clearance in mice with pancreas perfusions and pancreas-liver perfusions while measuring insulin levels in the portal vein and the inferior vena cava. The difference between the two perfusions provided a measure of hepatic extraction. Their findings indicated that Slc30a8-KO mouse livers had enhanced single-pass insulin clearance (3). A puff of $\mathrm{Zn}^{2+}$ accompanies every burst of insulin secretion (7). The authors hypothesized that $\mathrm{Zn}^{2+}$ inhibits insulin secretion and hepatic insulin uptake, and, therefore, loss of the $\mathrm{ZnT} 8$ transporter should relieve the inhibition of insulin secretion while simultaneously increasing hepatic insulin uptake. In support of this hypothesis, direct $\mathrm{Zn}^{2+}$ injection into the portal vein of mice or incubation with a hepatocyte cell line directly inhibited insulin uptake. In agreement with previous studies, deletion of Slc30a8 resulted in dramatic reduction of insulin crystals. Despite abnormal DCVs, more insulin was secreted, but was balanced by increased hepatic clearance. Conversely, studies in isolated islets and perfused pancreas showed that $\mathrm{Zn}^{2+}$ inhibits insulin secretion (3).

It has been proposed that $\beta$ cell-derived $\mathrm{Zn}^{2+}$ acts on $\alpha$ cells to suppress the glucagon secretion that accompanies insulin secretion. However, Tamaki et al. did not observe any difference in glucagon secretion in the Slc30a8-KO mice. Together with prior studies (8), these data suggest that the $\mathrm{Zn}^{2+}$ cosecreted with insulin is not responsible for the suppressive effect of insulin secretion on glucagon secretion.

\section{Differing phenotypes}

There is a lack of consensus on the effect of Slc30a8 deletion on insulin secretion and circulation in mice (Table 1$)$. In all reports, the consequence of Slc30a8 deletion appears to be relatively small. Studies using different mouse colonies with whole-body Slc30a8 deletion all agreed that $S l c 30 a 8$ deletion does not affect glucose homeostasis in mice fed a normal chow diet. The studies disagreed on the role of Slc30a8 on proinsulin processing, glucose-stimulated insulin secretion (GSIS), and glucose tolerance. Nicolson et al. showed that while their male KO mice process proinsulin normally, they are glucose intolerant, secrete significantly less insulin during an intraperitoneal glucose tolerance test, and have increased fasting glucose levels (9). Interestingly, GSIS was significantly elevated in isolated islets. Conversely, Pound et al. found that their Slc30a8-KO mice have normal glucose tolerance, but significantly reduced fasting plasma insulin levels, along with a $33 \%$ reduction in GSIS $(10,11)$. The Slc30a8-KO mice studied by Lemaire et al. lacked any significant phenotype when on normal chow (12). Another study reported that $\beta$ cell-specific deletion of Slc30a8 leads to decreased proinsulin processing, significantly reduced first-phase insulin secretion, and glucose intolerance during an oral glucose tolerance test (13).

Interestingly, there are fewer phenotypic differences between colonies of mice subjected to prolonged high-fat diet (HFD) feeding. The studies agreed that Slc30a8-KO mice fed HFD display greater weight gain, fasting hyperglycemia, fasting hyperinsu- 


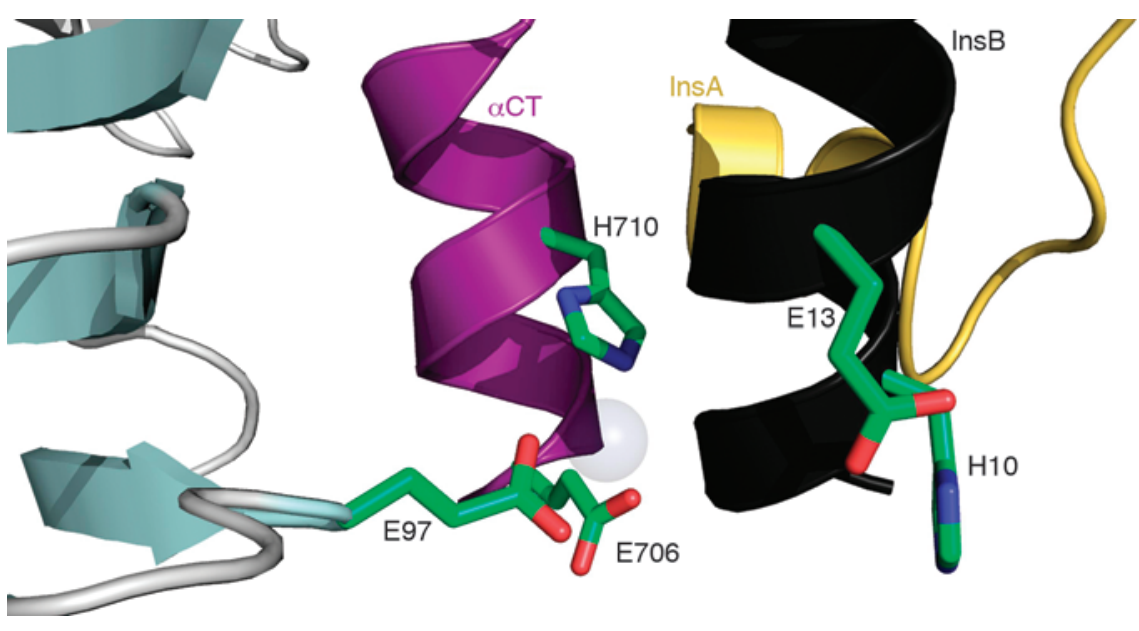

Figure 1

Putative $\mathrm{Zn}^{2+-b i n d i n g ~ r e s i d u e s ~ a t ~ t h e ~ I R-i n s u l i n ~ i n t e r f a c e . ~ M o d e l ~ o f ~ a ~ p u t a t i v e ~} \mathrm{Zn}^{2+-b i n d i n g ~ s i t e ~}$ in the insulin-binding site of the IR. The protein coordinates are from the IR-insulin crystal structure (PDB-ID 3W11). Insulin - chains InsA (gold) and InsB (black) are shown - engages with the IR at the $\alpha \mathrm{CT}$ (purple). The IR core particle $\beta$ strands are also shown (light cyan). A $\mathrm{Zn}^{2+}$ ion (transparent sphere) has been modeled in the structure based on the environment and known $\mathrm{Zn}^{2+}$-coordinating abilities of the highlighted residues. IR residues (green sticks) $\mathrm{H} 710$ and E706 (from the $\alpha \mathrm{CT}$ ) and E97 form a putative $\mathrm{Zn}^{2+}$-binding site. A water molecule or InsB side chains can complete the tetracoordinated $\mathrm{Zn}^{2+}$ site after helix rotation/displacement (not shown). Intriguingly, E706 forms a $\mathrm{H}$-bond to a backbone amide on InsB: this docking of the hormone with its receptor could be disrupted by binding of the zinc ion.

linemia, and glucose intolerance $(9,12,14)$. The role of Slc30a8 deletion on insulin sensitivity is still debated. Nicolson et al. (9) and Hardy et al. (14) reported decreased insulin sensitivity in their Slc30a8-KO colonies after prolonged HFD feeding; however, Lemaire et al. found insulin sensitivity to be unchanged (12).

Differences in genetic background may explain phenotypic differences. Pound et al. found that Slc30a8 deletion in two genetic backgrounds renders different phenotypes. They also reported sex-specific effects on resulting Slc30a8 deletion phenotypes (10). Finally, Slc30a8 deletion in mouse $\alpha$ cells did not produce a visible phenotype (13).

\section{Linking insulin, zinc, and the liver}

Deletion of PCSK1, a proprotein convertase that processes proinsulin, also blocks mature insulin formation and produces $\beta$ cell DCVs that are essentially devoid of aggregated insulin. The mice have hyperproinsulinemia, but apparently normal glucose tolerance (15). Thus, disruption of DCV maturation does not always lead to impaired regulated secretion. Like SLC30A8, PCSK1 has emerged as a genetic factor of T2D. Deficiency of these genes appears tolerable in animals with a normal demand for insulin secretion, but might produce a bot- tleneck when challenged by the increased demand posed by insulin resistance.

How might $\mathrm{Zn}^{2+}$ influence hepatic extraction of insulin? Tamaki et al. showed that $\mathrm{Zn}^{2+}$ levels did not affect the activity of the insulin-degrading enzyme. This observation is consistent with the effect of $\mathrm{Zn}^{2+}$ being restricted to insulin internalization. Blockade of insulin internalization was enhanced by pyrithione, a $\mathrm{Zn}^{2+}$ ionophore. This suggests that internalized $\mathrm{Zn}^{2+}$ is responsible for the inhibitory effect; however, the effect was independent of the $\mathrm{Zn}^{2+}$ transporter ZIP-14.

Tamaki et al. make the case that pulsatile release of $\mathrm{Zn}^{2+}$ inhibits clathrin-dependent insulin endocytosis via a complex with the insulin receptor (IR). Two physiochemical features of $\mathrm{Zn}^{2+}$ binding to proteins may provide an additional and direct antagonistic effect on IR-insulin interaction. First, $\mathrm{Zn}^{2+}$ is known to stabilize the hexameric form of insulin in plasma, which may not bind as tightly to the IR. Second, $\mathrm{Zn}^{2+}$ may be a competitive inhibitor at the insulin-binding site of IR, acting as an antagonist of insulin binding and/or internalization. In many $\mathrm{Zn}^{2+}$-dependent proteins, $\mathrm{Zn}^{2+}$ forms between three and five tight coordinate covalent bonds to side chains such as His, Glu, Asp, and Cys. Inspection of a recent IR structure (16) revealed a cluster of $\mathrm{Zn}^{2+}$-binding histidine and glutamate residues directly adjacent to the insulin-docking site (Figure 1). One of these, H710, was recently shown to be critical in the interaction with insulin (16). We note that this histidine residue is within hydrogen bonding distance to E706, both of which are in the carboxyterminal $\alpha$ chain $(\alpha \mathrm{CT})$ helix of the insulin-binding pocket. With minimal conformational changes, these residues, along with E97 and/or D707 or a water molecule, could form a tetrahedral coordination environment favored for $\mathrm{Zn}^{2+}$ binding (Figure 1). This raises the possibility that $\mathrm{Zn}^{2+}$ influences insulin clearance in part through direct competition with insulin for IR binding. Intriguingly, insulin monomers contain a potential $\mathrm{Zn}^{2+}$ binding site. $\mathrm{H} 10$ of the insulin molecule is critical for $\mathrm{Zn}^{2+}$ binding the hexameric form, but is absent in insulin variants that do not bind to $\mathrm{Zn}^{2+}(17)$. The adjacent $\mathrm{E} 13$ is in proximity to coordinate to the same $\mathrm{Zn}^{2+}$ ion. It is unknown whether $\mathrm{Zn}^{2+}$ occupancy at these putative sites inhibits or perhaps stabilizes the IR-insulin interaction, as is the case for other hormone-receptor interactions (1).

Additional features of $\mathrm{Zn}^{2+}$-histidine coordination chemistry are relevant to insulin biology. The histidine-rich domain of $\mathrm{ZnT}$ is essential for $\mathrm{Zn}^{2+}$ binding. Through binding to two critical histidine residues, $\mathrm{Zn}^{2+}$ activates the $\mathrm{K}_{\text {ATP }}$ channel and hyperpolarizes $\beta$ cells, which leads to inhibition of insulin secretion (18). This potentially explains how reduced $\mathrm{Zn}^{2+}$ uptake by $\beta$ cells could promote increased insulin secretion.

\section{Future directions}

Answering the questions evoked by these findings will require interdisciplinary teams that can pair physical and imaging methods with receptor physiology in model systems. Can $\mathrm{Zn}^{2+}$ simultaneously bind histidine and glutamate side chains in the IR and insulin to stabilize the complex and/or to prevent internalization? Are the relative $\mathrm{Zn}^{2+}$ affinities of the receptor, hormone, and heterodimeric complex compatible with the transient concentration gradient produced by pulsed $\mathrm{Zn}^{2+}$ release into the portal vein? Does $\mathrm{Zn}^{2+}$ only block insulin internalization, or does it also block insulin signaling? Answers to this question might help distinguish binding and signaling events. Are there other receptors that bind $\mathrm{Zn}^{2+}$ and are affected by the insulin secretion-dependent $\mathrm{Zn}^{2+}$ burst? How much $\mathrm{Zn}^{2+}$ escapes hepatic clearance and albumin binding to exert actions on extrahepatic tissues? 
Although fasting insulin is used as a surrogate measure of insulin resistance, it has a stronger correlation with insulin clearance, which is highly heritable $(19,20)$. Future human genetic studies will be important for determining whether genetic variation in SLC3OA8 contributes to T2D entirely through its effect on insulin clearance and how much of the heritability of insulin clearance is due to SLC30A8.

These studies illustrate how in-depth phenotyping, which requires model organisms, can take clues from human genetics and provide mechanistic explanations for relationships between genetic variation and human disease. Results from these studies can now be used to study subphenotypes associated with diabetes susceptibility. In this case, it may motivate study of the relationship among inorganic physiology (such as the $\mathrm{Zn}^{2+}$ fluxes described here), genetic variation at the SLC30A8 locus, and insulin clearance. Most importantly, these deeper phenotypes should be present in nondiabetics, and thus can be studied independently of the disease.

Address correspondence to: Thomas V. O'Halloran, Northwestern University, 2145 Sheridan Road, Evanston, Illinois 60208-3113, USA. Phone: 847.491.5060; Fax: 847.467.1566; E-mail: t-ohalloran@ northwestern.edu. Or to: Alan D. Attie, University of Wisconsin-Madison, 433 Babcock Drive, Madison, Wisconsin 53706, USA. Phone: 608.262.1372; Fax: 608.262.4705; E-mail: adattie@wisc.edu.

1. Kim AM, et al. Zinc sparks are triggered by fertilization and facilitate cell cycle resumption in mammalian eggs. ACS Chem Biol. 2011;6(7):716-723.

2. Outten CE, O'Halloran TV. Femtomolar sensitivity of metalloregulatory proteins controlling zinc homeostasis. Science. 2001;292(5526):2488-2492.

3. Tamaki $\mathrm{M}$, et al. The diabetes-susceptible gene SLC30A8/ZnT8 regulates hepatic insulin clearance. J Clin Invest. 2013;123(10):4513-4524.

4. Chimienti F, Devergnas S, Favier A, Seve M. Identification and cloning of a $\beta$-cell-specific zinc transporter, ZnT-8, localized into insulin secretory granules. Diabetes. 2004;53(9):2330-2337.

5 . Wenzlau JM, et al. The cation efflux transporter ZnT8 (Slc30A8) is a major autoantigen in human type 1 diabetes. Proc Natl Acad Sci U S A. 2007;104(43):17040-17045.

6. Sladek R, et al. A genome-wide association study identifies novel risk loci for type 2 diabetes. Nature. 2007;445(7130):881-885

7. Qian WJ, Gee KR, Kennedy RT. Imaging of $\mathrm{Zn}^{2+}$ release from pancreatic $\beta$-cells at the level of single exocytotic events. Anal Chem. 2003;75(14):3468-3475.

8. Cheng-Xue R, et al. Tolbutamide controls glucagon release from mouse islets differently than glucose: involvement of K(ATP) channels from both $\alpha$-cells and $\delta$-cells. Diabetes. 2013;62(5):1612-1622.

9. Nicolson TJ, et al. Insulin storage and glucose homeostasis in mice null for the granule zinc transporter $\mathrm{ZnT} 8$ and studies of the type 2 diabetes-associated variants. Diabetes. 2009;58(9):2070-2083

10. Pound LD, et al. The physiological effects of delet- ing the mouse SLC30A8 gene encoding zinc transporter- 8 are influenced by gender and genetic background. PLoS One. 2012;7(7):e40972.

11. Pound LD, et al. Deletion of the mouse Slc30a8 gene encoding zinc transporter-8 results in impaired insulin secretion. Biochem J. 2009;421(3):371-376.

12. Lemaire $\mathrm{K}$, et al. Insulin crystallization depends on zinc transporter $\mathrm{ZnT} 8$ expression, but is not required for normal glucose homeostasis in mice. Proc Natl Acad Sci U S A. 2009;106(35):14872-14877.

13. Wijesekara N, et al. Beta cell-specific Znt8 deletion in mice causes marked defects in insulin processing, crystallisation and secretion. Diabetologia. 2010;53(8):1656-1668.

14. Hardy $A B$, et al. Effects of high-fat diet feeding on Znt8-null mice: differences between $\beta$-cell and global knockout of Znt8. Am J Physiol Endocrinol Metab. 2012;302(9):E1084-E1096.

15. Zhu X, Orci L, Carroll R, Norrbom C, Ravazzola M, Steiner DF. Severe block in processing of proinsulin to insulin accompanied by elevation of des-64,65 proinsulin intermediates in islets of mice lacking prohormone convertase 1/3. Proc Natl Acad SciUS A. 2002;99(16):10299-10304.

16. Menting JG, et al. How insulin engages its primary binding site on the insulin receptor. Nature. 2013;493(7431):241-245.

17. Beintema JJ, Campagne RN. Molecular evolution of rodent insulins. Mol Biol Evol. 1987;4(1):10-18.

18. Bancila V, et al. Two SUR1-specific histidine residues mandatory for zinc-induced activation of the rat KATP channel. J Biol Chem. 2005;280(10):8793-8799.

19. Goodarzi MO, et al. Systematic evaluation of validated type 2 diabetes and glycaemic trait loci for association with insulin clearance. Diabetologia. 2013;56(6):1282-1290.

20. Goodarzi MO, Cui J, Chen YD, Hsueh WA, Guo $\mathrm{X}$, Rotter JI. Fasting insulin reflects heterogeneous physiological processes: role of insulin clearance. Am JPhysiol Endocrinol Metab. 2011;301(2):E402-E408.

\title{
Opening lines of communication in the distal nephron
}

\author{
Thomas R. Kleyman, ${ }^{1}$ Lisa M. Satlin, ${ }^{2}$ and Kenneth R. Hallows ${ }^{1}$
}

\begin{abstract}
${ }^{1}$ Renal-Electrolyte Division, Department of Medicine, and Department of Cell Biology, University of Pittsburgh School of Medicine, Pittsburgh, Pennsylvania, USA. ${ }^{2}$ Department of Pediatrics, The Icahn School of Medicine at Mount Sinai, New York, New York, USA.
\end{abstract}

\begin{abstract}
The distal nephron is composed of two main cell types: principal cells and intercalated cells. These cells have distinct morphologic features that allow them to be readily distinguished by light microscopy, as well as distinct suites of proteins that facilitate cell-specific transport properties. In this issue of the JCI, Gueutin and colleagues describe a new mechanism by which $\beta$-intercalated cells, via release of ATP and prostaglandin $\mathrm{E}_{2}\left(\mathrm{PGE}_{2}\right)$, influence the activity of transporters in principal cells.
\end{abstract}

\section{Challenging tradition}

The traditional view of the distal nephron considers principal cells to be primarily

Conflict of interest: Kenneth R. Hallows is the principal investigator of a grant to the University of Pittsburgh from Dialysis Clinics Inc. to study the role of kinases in kidney epithelial transport regulation.

Citation for this article: J Clin Invest. 2013; 123(10):4139-4141. doi:10.1172/JCI71944. responsible for reabsorption of filtered $\mathrm{Na}^{+}$ and for $\mathrm{K}^{+}$secretion into the ultrafiltrate, whereas intercalated cells account for urinary acidification. Sodium reabsorption by principal cells occurs via the $\mathrm{Na}^{+} / \mathrm{Cl}^{-}$ cotransporter (NCC) in the early distal nephron and the epithelial $\mathrm{Na}^{+}$channel $(\mathrm{ENaC})$ in later nephron segments. Potassium is secreted via the renal outer med- ullary $\mathrm{K}^{+}$channel (ROMK; Figure $1 \mathrm{~A}$ ). Intercalated cells are primarily responsible for urinary acidification, through $\mathrm{H}^{+}$ secretion by the vacuolar $\mathrm{H}^{+}$-ATPase or the $\mathrm{H}^{+} / \mathrm{K}^{+}$-ATPase found in $\alpha$-intercalated cells. When required, $\mathrm{HCO}_{3}{ }^{-}$secretion into the ultrafiltrate occurs via the $\mathrm{Cl}^{-} / \mathrm{HCO}_{3}$ exchanger pendrin (also known as SLC4A4) in $\beta$-intercalated cells $(1,2)$. This view presumes limited crosstalk between principal and intercalated cells, as a lack of gap junctions between these cell types limits their communication $(3,4)$.

As we learn more about properties of the distal nephron, distinctions between principal and intercalated cells are beginning to fade. Recent studies have shown 